\title{
Article \\ MCPIP1/Regnase-1 Expression in Keratinocytes of Patients with Hidradenitis Suppurativa: Preliminary Results
}

\author{
Piotr K. Krajewski ${ }^{1,+}{ }^{\oplus}$, Weronika Szukała ${ }^{2,+}{ }^{\oplus}$, Agata Lichawska-Cieślar ${ }^{2, *}$, tukasz Matusiak ${ }^{1}$, Jolanta Jura ${ }^{2}(\mathbb{D}$ \\ and Jacek C. Szepietowski ${ }^{1, *}$ (i) \\ 1 Department of Dermatology, Venereology and Allergology, Wroclaw Medical University, Chalubinskiego 1, \\ 50-368 Wroclaw, Poland; piotr.krajewski@student.umed.wroc.pl (P.K.K.); luke71@interia.pl (Ł.M.) \\ 2 Department of General Biochemistry, Faculty of Biochemistry, Biophysics and Biotechnology, Jagiellonian \\ University, Gronostajowa 7, 30-392 Krakow, Poland; weronika.szukala@doctoral.uj.edu.pl (W.S.); \\ jolanta.jura@uj.edu.pl (J.J.) \\ * Correspondence: agata.lichawska@uj.edu.pl (A.L.-C.); jacek.szepietowski@umed.wroc.pl (J.C.S.) \\ + These authors contributed equally.
}

Citation: Krajewski, P.K.; Szukała, W.; Lichawska-Cieślar, A.; Matusiak, Ł.; Jura, J.; Szepietowski, J.C. MCPIP1/Regnase-1 Expression in Keratinocytes of Patients with Hidradenitis Suppurativa: Preliminary Results. Int. J. Mol. Sci. 2021, 22, 7241. https://doi.org/10.3390/ijms22147241

Academic Editor: Thomas Litman

Received: 7 June 2021

Accepted: 4 July 2021

Published: 6 July 2021

Publisher's Note: MDPI stays neutral with regard to jurisdictional claims in published maps and institutional affiliations.

Copyright: (c) 2021 by the authors. Licensee MDPI, Basel, Switzerland. This article is an open access article distributed under the terms and conditions of the Creative Commons Attribution (CC BY) license (https:// creativecommons.org/licenses/by/ $4.0 /)$.

\begin{abstract}
The pathogenesis of hidradenitis suppurativa (HS) is yet to be fully understood. However, inflammation is a key element in the development of skin lesions. The aim of this study was to evaluate the expression of monocyte chemotactic protein-1-induced protein-1 (MCPIP1) in the skin of patients suffering from HS. Skin biopsies of 15 patients with HS and 15 healthy controls were obtained and processed for immunohistochemistry, western blot, and real time PCR. The highest mean MCPIP1 mRNA expression was found in the inflammatory lesional skin of HS patients. It was significantly higher than MCPIP1 mRNA expression in the biopsies from both healthy controls and non-lesional skin of HS patients. Western blot analysis indicated that expression of MCPIP1 was elevated within both lesional and non-lesional skin compared to the healthy control. The increased MCPIP1 mRNA and protein expression level in HS lesions may indicate its possible role in the disease pathogenesis.
\end{abstract}

Keywords: MCPIP1; hidradenitis suppurativa; Regnase-1

\section{Introduction}

Inflammation is a basic immune response of our organism that enables survival during infections or injuries. On the molecular level, it is a set of interactions between inflammatory factors and cells, often described as a stress response of tissue or organism to noxious conditions [1,2]. Although usually beneficial and life-preserving, disturbances of the innate immune system may lead to development of immune-mediated diseases [3]. Moreover, failure in neutralizing acute response often causes chronic inflammation and severe metabolic consequences [4]. Many of the important immune responses are carried out in the skin [5].

Hidradenitis suppurativa (HS) is a debilitating skin disorder of a complex pathogenesis, which remains unclear [6]. The role of overproduction of inflammatory cytokines and an inability of its inhibition has been mentioned by many authors [7]. The possible suppression of inflammation is of benefit for the treatment of HS [8-10].

Monocyte chemotactic protein-1-induced protein-1 (MCPIP1), also known as Regnase-1, is an RNase protein encoded by the $\mathrm{ZC} 3 \mathrm{H} 12 \mathrm{~A}$ gene. It regulates the inflammatory activation and maintains immune homeostasis by selectively promoting the destabilization of mRNAs of certain proinflammatory cytokines (e.g., IL-6 and IL-1 $\beta$ ) and transcription factors [11-15]. The lack of MCPIP1 in mice resulted in systemic inflammation leading to growth retardation, anemia, splenomegaly, lymphadenopathy, and premature death [11,16-18]. Recent studies indicated that in the skin, MCPIP1 functions as an important regulator of epidermal homeostasis. The $\mathrm{ZC} 3 \mathrm{H} 12 \mathrm{~A}$ gene is induced by many inflammatory mediators including 
IL-17 and IL-36 [19-21]. Our previous studies on the influence of MCPIP1 on keratinocytes showed that its deficiency leads to the skin barrier impairment and spontaneous cutaneous inflammation [22]. On the other hand, MCPIP1 was shown to be upregulated in human psoriatic skin $[20,23]$, whereas its deficiency in mice led to the much aggravated psoriasis-like inflammation phenotype induced by imiquimod [21,23,24].

We hypothesized that MCPIP1 may be involved in the pathogenesis of other than psoriasis skin disorders of inflammatory background, like HS. The aim of this study was to evaluate the expression of MCPIP1, both on mRNA and protein level, in the skin of patients suffering from HS. To the best of our knowledge, this is the first study to investigate the possible association between MCPIP1 and the pathogenesis of HS.

\section{Results}

\section{MCPIP1 Is Aberrantly Expressed in Hidradenitis Suppurativa}

To investigate potential association of MCPIP1 with HS, we analyzed the expression of MCPIP1 on both mRNA and protein levels in the lesional and non-lesional skin of HS patients, and healthy controls. The highest mean MCPIP1 mRNA expression was found in the inflammatory lesional skin of HS patients (HS-1: lesional skin) $(0.0236 \pm 0.0134)$. It was significantly higher than MCPIP1 mRNA expression in the biopsies from both healthy controls (CTR) $(0.0080 \pm 0.0034, p<0.001)$ and non-lesional skin of HS patients (HS-2: non-lesional skin) $(0.0049 \pm 0.0034, p<0.001)$ (Figure 1A). There were no statistical correlations between MCPIP1 mRNA expression in lesional HS skin and well-known HS predisposing factors (obesity and smoking), as well as between sexes, those with and without family history of HS or those who had or had not suffered from juvenile acne in their adolescence (detailed data not shown). We next determined MCPIP1 protein expression in the lysates of control and HS skin. Western blot analysis indicated that expression of MCPIP1 was elevated within both lesional (2,5-fold increase) and non-lesional skin (2,3-fold increase) compared to the healthy control (Figure 1B,C). Subsequently, we determined the in situ expression of MCPIP1 in the skin. Generally, all biopsies showed a similar pattern of immunostaining. Specific MCPIP1 immunostaining was cytoplasmic and present in the epidermis, as well as in hair follicles. MCPIP1 immunoreactivity was found in all studied biopsies (HS-1: lesional skin, HS-2: non-lesional skin and healthy control skin) in the suprabasal layers of the epidermis. The basal layer of the epidermis showed no MCPIP1 immunoreactivity. There was also no MCPIP1 immunoreactivity in the dermis. Both lesional and non-lesional HS skin showed aberrant distribution of MCPIP1 within epidermis (Figure 1D).

In parallel to the analyses of MCPIP1 expression, we investigated the level of inflammatory influx within HS skin. Haematoxylin and eosin staining showed a large inflammatory cell infiltration into the dermis of HS lesional skin (Figure 2A). This correlated with increased gene expression level of selected inflammatory mediators: IL-1 $\beta$, IL-6, TNF $\alpha$ and S100A8 (Figure 2B). The non-lesional HS skin did not show any signs of inflammatory reaction (Figure $2 \mathrm{~A}, \mathrm{~B}$ ).

A

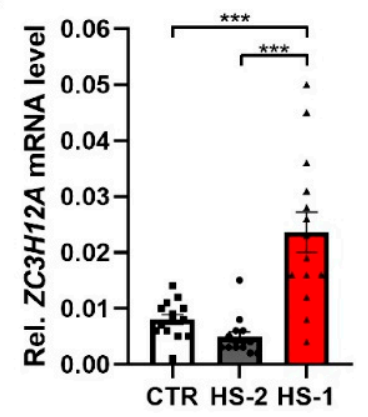

B

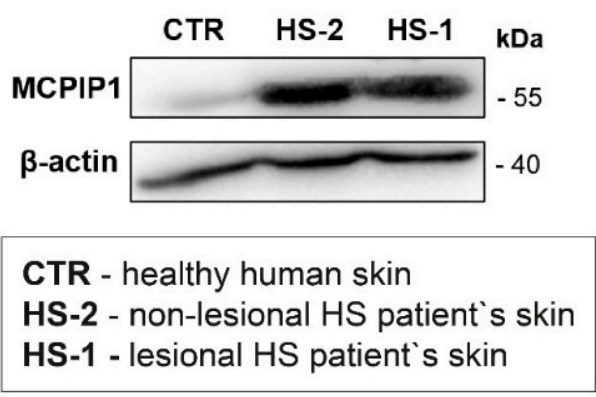

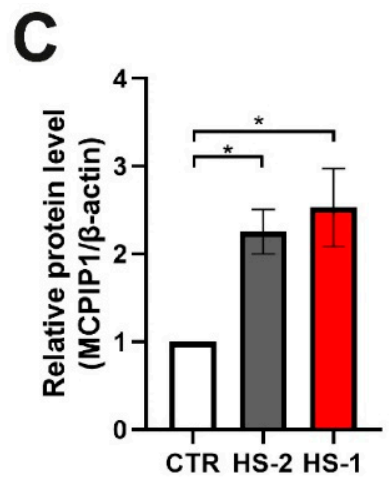

Figure 1. Cont. 
D

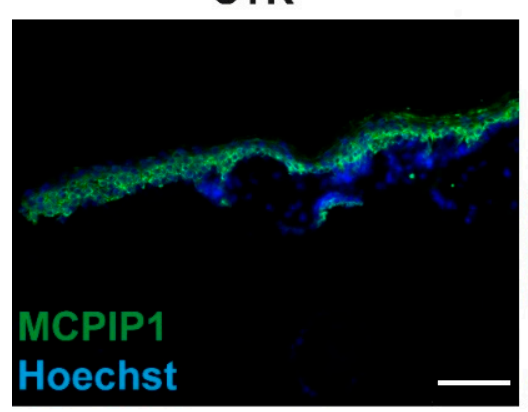

HS-2

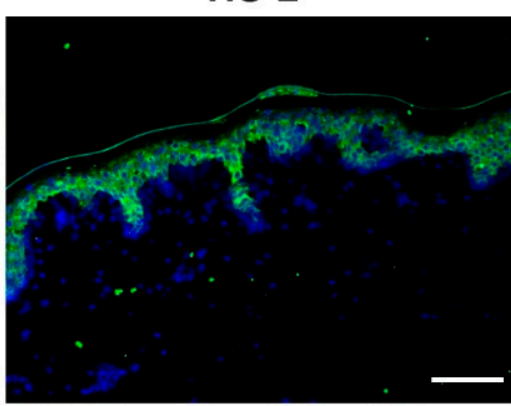

HS-1

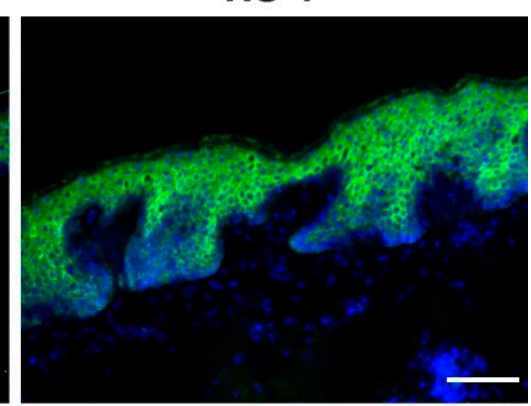

Figure 1. Increased expression of monocyte chemotactic protein-1-induced protein-1 (MCPIP1) in the hidradenitis suppurativa skin. (A) qRT-PCR analysis of MCPIP1 (ZC3H12A) transcript level in the healthy human skin (CTR), non-lesional hidradenitis suppurativa patients' skin (HS-2) and lesional HS patients' skin (HS-1) $(n=14)$. (B) Representative Western blot for MCPIP1. $\beta$-actin was used as the loading control. (C) Densitometric quantification of MCPIP1 protein level $(n=4)$. (D) Representative MCPIP1 immunofluorescence staining of the skin sections. Scale bar $100 \mu \mathrm{m}$. Data represent the mean \pm SEM. ${ }^{*} p<0.05,{ }^{* * *} p<0.001$ by one-way ANOVA.
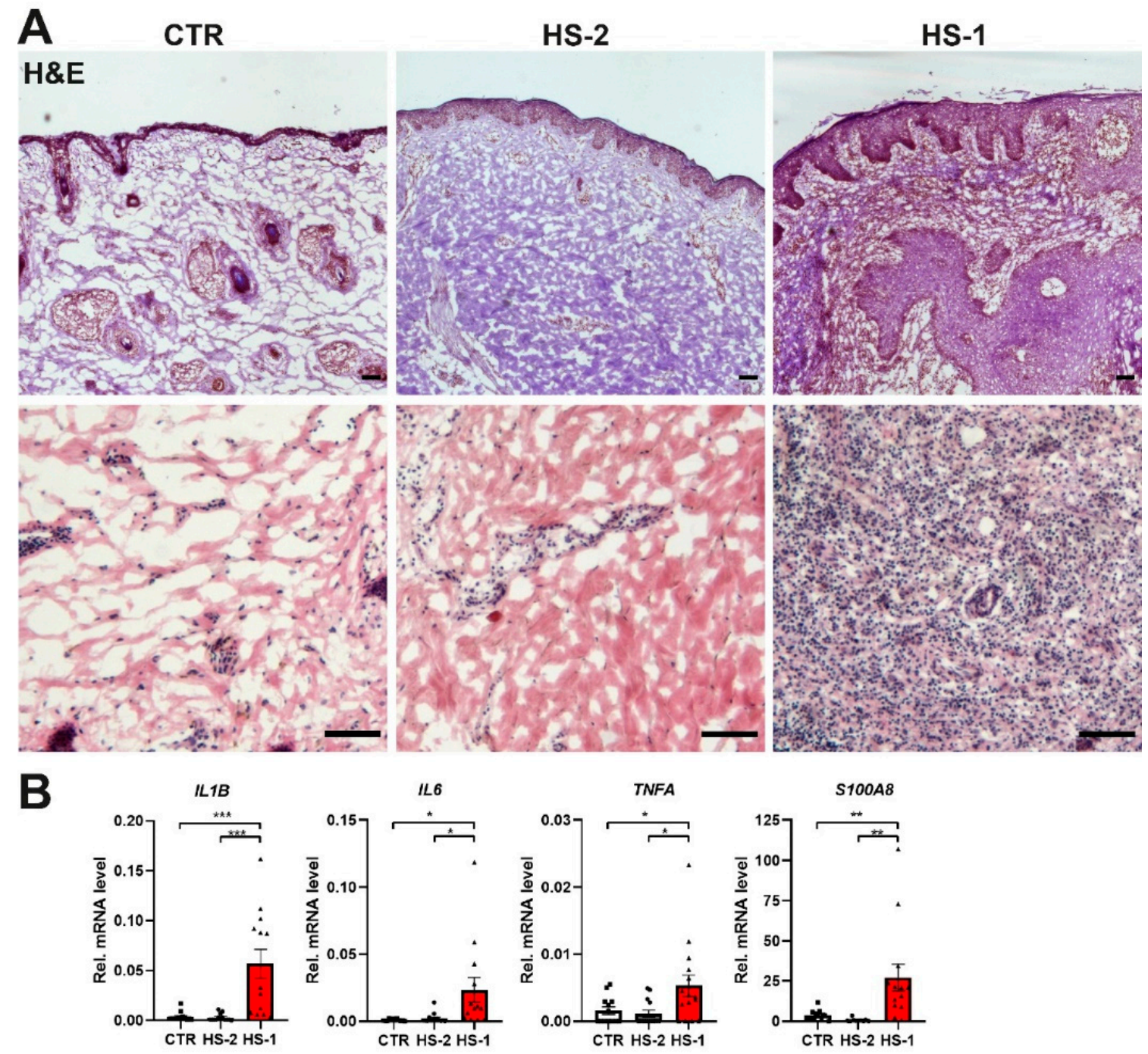

Figure 2. Abundant inflammation in the hidradenitis suppurativa skin. (A) H\&E staining of the CTR, HS-1, and HS-2 skin sections at different magnification. (B) qRT-PCR analysis of IL1B, IL6, TNFA and S100A8 transcript level. Scale bar $100 \mu \mathrm{m}$. Data represent the mean \pm SEM. ${ }^{*} p<0.05,{ }^{* *} p<0.01,{ }^{* * *} p<0.001$ by one-way ANOVA. 


\section{Discussion}

The pathogenesis of HS is yet to be fully understood. Among several proposed pathogenetic factors (obesity, smoking, hormonal disbalance, genetic predisposition) immunological disturbances are considered crucial for the development of HS lesions. The involvement of the immune system and disruption in the immune response have been confirmed with the favorable outcome of anti-inflammatory biologic treatment [8-10].

The results of our study clearly demonstrate the increased MCPIP1 mRNA and protein expression in the lesional skin of HS patients. Our results are comparable with those reported in psoriatic plaques [20,23]. Similarly to our study, MCPIP1 mRNA and protein expression was significantly increased in psoriatic skin than in healthy control skin samples. The similarities between both studies confirm a possible mutual immune-pathogenetic pathway of HS and psoriasis. Higher MCPIP1 expression and its function in inflammatory regulation may play an important role in the pathogenesis of both disorders. As hypothesized by Monin et al. [23] it is likely that the increased MCPIP1 mRNA expression reflects the ongoing inflammatory milieu, and particularly the high IL-17A levels, demonstrated in lesional skin of both HS and psoriasis. This is not surprising as the resemblances between HS and psoriasis have already been found in pathogenesis and treatment in both disorders [25].

We observed that the level of MCPIP1 protein was elevated not only within lesional skin, but also in the skin surrounding the HS lesion. In that region MCPIP1 was stabilized, most likely as a result of a highly inflammatory environment. This, however, did not correlate with increased transcriptional expression of ZC3H12A. This may be explained by the fact that MCPIP1 RNase regulates, among many other mRNAs, also its own transcript half-live [26].

To the best of our knowledge, this is the third study in which MCPIP1 expression was assessed in human skin. Ruiz-Romeu et al. [20] in healthy skin found the expression of MCPIP1 exclusively present in the granular layer of the epidermis. A similar pattern of MCPIP1 immunoreactivity was found in atopic dermatitis [20]. In contrast, Monin L et al. [23] demonstrated MCPIP1 expression distributed in the whole epidermis of the healthy skin. Our study clearly showed MCPIP1 immunoreactivity in the suprabasal layers of the epidermis of healthy controls. In HS lesional skin we demonstrated abundant MCPIP1 immunoreactivity in the suprabasal layers of the epidermis with comparable immunostaining pattern as in non-lesional HS skin and healthy control skin. In lesional psoriatic skin MCPIP1 immunoreactivity was also predominantly found in the epidermis, distributed equally in the entire epidermis [23] or in its upper layers [20]. In both studies MCPIP1 immunoreactivity was similarly localized both in lesional and non-lesional psoriatic skin $[20,23]$.

In the lesional skin of HS, MCPIP1 is elevated on both transcriptional and translational level and it is not sufficient to resolve inflammatory processes. We noticed high inflammatory influx and elevated transcriptional expression of selected HS-related factors: IL-1 $\beta$, IL-6, TNF $\alpha$ and S100A8. Enhanced expression of IL- 6 and IL- $1 \beta$ was demonstrated in the lesional skin of HS patients [27]. Expression of S100A8/A9 was also shown to be elevated in HS [28]. Moreover, increased levels of TNF $\alpha$ in HS patient serum and skin have been reported [29-32].

Another molecule that may be important in HS pathogenesis is the seventh subunit of $\mathrm{P} 2 \mathrm{X}$ receptor $(\mathrm{P} 2 \times 7 \mathrm{R})$, which is plasma membrane channel gated by adenosine triphosphate (ATP) [33]. It is widely distributed, especially in immune system cells. Its role is to activate the NLRP3 inflammasome and promote IL- $1 \beta$ maturation and release. The receptor have been previously described in psoriasis, rosacea, and HS [34-36]. Manfredini et al. [35] found that P2X7R protein level is higher in keratinocytes, lymphocytes, and monocytes of HS skin in comparison to healthy controls [35]. Moreover, authors presented, that P2X7R has significant, yet weak association with NLRP3 inflammasome [35].

We are aware of limitations of our study. Firstly, our group consisted only of 15 people suffering from HS. Although the population of well diagnosed HS patients is small, the 
number of patients in future studies should be bigger in order to provide more accurate data. Moreover, we have focused on MCPIP1 and its expression in the skin of HS patient. Future studies aiming for correlation between MCPIP1 and well-known proinflammatory molecules, including newly described P2X7R, would play an important role in discovering the pathogenesis of HS.

\section{Materials and Methods}

The study was approved by the local Bioethics Committee of Wroclaw Medical University. The studied group included 15 patients with HS: 7 females (46.67\%) and 8 males $(53.55 \%)$. The mean age of the group was $35.8 \pm 11.2$ years. According to the mean BMI $\left(30.1 \pm 6.31 \mathrm{~kg} / \mathrm{m}^{2}\right)$ the population was considered obese. The majority (8 people, $\left.53.6 \%\right)$ of the subjects were active smokers with the mean of $9.6 \pm 6.1$ pack-years. 7 people $(46.7 \%)$ reported to suffer from juvenile acne during adolescence, while only $2(13.3 \%)$ had a positive family history of HS. A total $86.7 \%$ (13) of patients were treated previously, with unsatisfactory results. All included patients have not been treated for HS for at least of two months before the enrollment to the study. All the patients were examined by the dermatologists experienced with HS, in order to properly assess HS severity. According to Hurley staging [37] the severity of the disease in the majority of the patients was assessed as Hurley II (8 patients, $53.3 \%)$, in 4 subjects (26.7\%) as Hurley III and in the rest (3 people, 20\%) as Hurley I. As for IHS4 assessment [38], on average the patients scored $15.9 \pm 8.9$ points, indicating severe disease. Among the HS-associated subjective symptoms, assessed with 11-point Numeral Rating Scale (NRS), pain was the most severe ( $4.4 \pm 2.9$ points), then purulent discharge ( $4.2 \pm 2.9$ points), foul smell ( $3.4 \pm 3.4$ points) and pruritus (2.5 \pm 2.6 points). 9 patients $(60 \%)$ had multiple body areas affected by HS, while $6(40 \%)$ presented HS limited to one area. Among the most frequently affected areas were armpits (11 patients, $73.3 \%$ ), while buttocks affectation was present in only 1 subject $(6.7 \%)$.

Additionally, 15 control healthy skin samples were collected from the age and sexmatched patients who underwent surgical procedures for non-malignant skin lesions or blepharoplasty.

\subsection{Biopsy}

Prior to the biopsy, the patients got locally injected the mixture of anesthetic ( $2 \%$ lidocaine) and adrenaline to diminish pain and impede bleeding. Two 5-mm punch biopsies were obtained from every HS patient. One of the biopsies was taken from the active, inflammatory lesion, while the other from the healthily looking skin in close proximity from the first one (at least $2 \mathrm{~cm}$ ).

\subsection{RNA Isolation and Quantitative Real-Time PCR}

All collected skin samples were frozen in RNAlater (Sigma-Aldrich, Saint Louis, MO, USA) and stored at $-80^{\circ} \mathrm{C}$. Total RNA was extracted from tissues by homogenization in Fenozol (A\&A Biotechnology, Gdynia, Poland) using a tissue homogenizer (Miccra D-1, Miccra GmbH, Germany). The purity and concentration of total RNA were assessed using a NanoDrop 1000 spectrophotometer (Thermo Fisher Scientific, Waltham, MA, USA). Subsequently, $1 \mu \mathrm{g}$ of total RNA was reverse-transcribed with oligo(dT) primer and M-MLV reverse transcriptase (Promega, Madison, WI, USA). The cDNA was diluted 5 times, and real-time PCR was performed using a QuantStudio 3 system (Applied Biosystems, Thermo Fisher Scientific, Waltham, MA, USA) with SYBR Green qPCR master mix (A\&A Biotechnology, Gdynia, Poland). The mRNA level of MCPIP1 transcript was determined relative to elongation factor-2 (EF2) by the $2^{-\Delta \mathrm{Ct}}$ method. The following gene-specific primer pairs were used: for ZC3H12A: GGAAGCAGCCGTGTCCCTATG and TCCAGGCTGCACTGCTCACTC, for EF2: GACATCACCAAGGGTGTGCAG and TCAGCACACTGGCATAGAGGC, for IL1B: GATGTCTGGTCCATATGAACTG and TTGGGATCTACACTCTCCAGC, for IL6: GTGAAAGCAGCAAAGAGGCA and 
TCACCAGGCAAGTCTCCTCA, for TNFA: TAGCCCATGTTGTAGCAAACC and TGATGGCAGAGAGGAGGTTG, for S100A8: GAATTTCCATGCCGTCTACAGG and GCCACGCCCATCTTTATCACCAG.

\subsection{Western Blot Analysis}

The protein lysate from skin tissues was isolated in RIPA (Radioimmunoprecipitation assay buffer) solution with protease and phosphatase inhibitors (Roche, Basely, Switzerland) using a tissue homogenizer and then centrifuged for $20 \mathrm{~min}, 4^{\circ} \mathrm{C}, 14,000 \times \mathrm{g}$. The protein concentrations in the tissues lysates were measured with the bicinchoninic acid assay. The electrophoresis separation was carried out in $10 \%$ polyacrylamide gel and electrotransferred to PVDF (Polyvinylidene fluoride) membranes (Merck-Millipore, Burlington, MA, USA). After the transfer, membranes were blocked for $1 \mathrm{~h}$ in 3\% milk in Tris-buffered saline with $0.05 \%$ Tween (BioShop, Burlington, ON, Canada) followed by an overnight incubation in the primary antibody at $4{ }^{\circ} \mathrm{C}$. On the following day, the membranes were rinsed and incubated for $1 \mathrm{~h}$ with the secondary antibody. The Immobilon TM Western Chemiluminescent HRP Substrate (Merck-Millipore, Burlington, MA, USA) and the ChemiDoc system (Bio-Rad, Hercules, CA, USA) were used for signal detection. Densitometric quantification was performed using ImageLab (Bio-Rad, Hercules, CA, USA). The MCPIP1 protein level was normalized to $\beta$-actin level. The following antibodies were used: rabbit anti-MCPIP1 (GTX110807; 1:2000; GeneTex, Inc., Irvine, CA, USA), mouse anti- $\beta$-actin (A1978; $1: 2000$; Sigma-Aldrich), peroxidase-conjugated anti-rabbit (A0545; 1:20,000; Sigma-Aldrich, St. Luis, MO, USA) and peroxidase-conjugated anti-mouse (1:20,000; BD Pharmingen).

\subsection{Immunofluorescence Staining}

Skin tissues were embedded in Tissue-Tek O.C.T. Compound (Scigen Scientific Gardena, Gardena, CA, USA) and stored at $-80^{\circ} \mathrm{C}$. Then, $8 \mu \mathrm{m}$ cryosections were cut and stained with hematoxylin and eosin (H\&E) using standard protocol. For immunofluorescence staining, antigen retrieval was performed in $10 \mathrm{mM}$ citrate buffer ( $\mathrm{pH}$ 6.0) for $30 \mathrm{~min}$ at $95^{\circ} \mathrm{C}$. Subsequently, skin samples were blocked with $5 \%$ horse serum, $1 \%$ BSA and $0.05 \%$ Tween in PBS for $1 \mathrm{~h}$ and incubated with primary rabbit antibodies against MCPIP1 (1:100; GeneTex) overnight at $4{ }^{\circ} \mathrm{C}$ in blocking buffer. Bound primary antibodies were detected by incubation with secondary goat antibodies Alexa Fluor 488 anti-rabbit (A11008; 1:600; Invitrogen, Darmstadt, Germany) for $1 \mathrm{~h}$ at room temperature, followed by counterstaining with Hoechst 33,258 (1:2500; Thermo Scientific). After incubation, the sections were mounted in fluorescent mounting medium (Dako) and visualized in Leica DMC5400B microscope (Leica Microsystems, Wetzlar, Germany). All figures were prepared using ImageJ (National Institutes of Health, Bethesda, MD, USA).

\subsection{Statistical Analysis}

The statistical analysis of the obtained results was performed with the use of IBM SPSS Statistics v. 26 (SPSS INC., Chicago, IL, USA) software. All data were assessed for parametric or non-parametric distribution. The minimum, maximum, mean and standard deviation numbers were calculated. Analyzed quantitative variables were evaluated using Mann-Whitney U test, Spearman and Pearson correlations, while for qualitative data test Chi2 was used. One-way ANOVA was used for the comparison of mRNA and protein expression levels between two HS samples and healthy skin. A 2-sided $p$ value of $\leq 0.05$ was considered to be statistically significant.

\section{Conclusions}

As far as we know, this is the first study assessing the expression of MCPIP1 in the skin of HS patients. Our preliminary results may be of benefit for the deeper understanding of the possible immunopathogenesis of this chronic and recurrent inflammatory dermatosis. Nevertheless, though our study sheds light on possible involvement of MCPIP1 in HS 
pathogenesis, further studies are necessary to clarify the exact role of MCPIP1 in the pathogenesis of HS.

Author Contributions: Conceptualization, J.J., J.C.S. and Ł.M.; methodology, J.J., J.C.S. and Ł.M.; investigation, P.K.K., W.S., A.L.-C., Ł.M., J.J. and J.C.S.; resources, P.K.K., W.S. and A.L.-C.; data curation, P.K.K., W.S., A.L.-C., Ł.M., J.J. and J.C.S.; writing—original draft preparation, P.K.K., W.S., A.L.-C., Ł.M., J.J. and J.C.S.; writing-review and editing, J.J., J.C.S. and Ł.M.; visualization, W.S. and A.L.-C.; supervision, J.J., J.C.S. and Ł.M.; project administration, P.K.K., J.C.S. and J.J. All authors have read and agreed to the published version of the manuscript.

Funding: Grant for young researchers of Wroclaw Medical University no. STM.C260.20.019.

Institutional Review Board Statement: The study was performed based on the statutory activity of the department, in accordance with the previously obtained approval of the Institutional Review Board of Wrocław Medical University (KB-520/2018).

Informed Consent Statement: Informed consent was obtained from all subjects involved in the study.

Data Availability Statement: The data obtained in this study may be available from the corresponding authors upon a reasonable request.

Conflicts of Interest: The authors declare no conflict of interest.

\section{References}

1. Medzhitov, R. Inflammation 2010: New adventures of an old flame. Cell 2010, 140, 771-776. [CrossRef]

2. Nathan, C. Points of control in inflammation. Nature 2002, 420, 846-852. [CrossRef]

3. Ozen, S. What's new in autoinflammation? Pediatr. Nephrol. 2019, 34, 2449-2456. [CrossRef]

4. Seelaender, M.; Neto, J.C.; Pimentel, G.D.; Goldszmid, R.S.; Lira, F.S. Inflammation in the disease: Mechanism and therapies 2014. Mediat. Inflamm. 2015, 2015, 169852. [CrossRef]

5. Pasparakis, M.; Haase, I.; Nestle, F.O. Mechanisms regulating skin immunity and inflammation. Nat. Rev. Immunol. 2014, 14, 289-301. [CrossRef]

6. Vekic, D.A.; Frew, J.; Cains, G.D. Hidradenitis suppurativa, a review of pathogenesis, associations and management. Australas. J. Dermatol. 2018, 59 Pt 1, 267-277. [CrossRef]

7. Prens, E.; Deckers, I. Pathophysiology of hidradenitis suppurativa: An update. J. Am. Acad. Dermatol. 2015, 73 (Suppl. 1), S8-S11. [CrossRef]

8. Wlodarek, K.; Ponikowska, M.; Matusiak, L.; Szepietowski, J.C. Biologics for hidradenitis suppurativa: An update. Immunotherapy 2019, 11, 45-59. [CrossRef]

9. Miller, I.; Lynggaard, C.D.; Lophaven, S.; Zachariae, C.; Dufour, D.N.; Jemec, G.B. A double-blind placebo-controlled randomized trial of adalimumab in the treatment of hidradenitis suppurativa. Br. J. Dermatol. 2011, 165, 391-398. [CrossRef]

10. Grant, A.; Gonzalez, T.; Montgomery, M.O.; Cardenas, V.; Kerdel, F.A. Infliximab therapy for patients with moderate to severe hidradenitis suppurativa: A randomized, double-blind, placebo-controlled crossover trial. J. Am. Acad. Dermatol. 2010, 62, 205-217. [CrossRef]

11. Matsushita, K.; Takeuchi, O.; Standley, D.M.; Kumagai, Y.; Kawagoe, T.; Miyake, T.; Satoh, T.; Kato, H.; Tsujimura, T.; Nakamura, H.; et al. Zc3h12a is an RNase essential for controlling immune responses by regulating mRNA decay. Nature 2009, 458, 1185-1190. [CrossRef]

12. Mizgalska, D.; Wegrzyn, P.; Murzyn, K.; Kasza, A.; Koj, A.; Jura, J.; Jarząb, B.; Jura, J. Interleukin-1-inducible MCPIP protein has structural and functional properties of RNase and participates in degradation of IL-1beta mRNA. FEBS J. 2009, 276, 7386-7399. [CrossRef]

13. Uehata, T.; Akira, S. mRNA degradation by the endoribonuclease Regnase-1/ZC3H12a/MCPIP-1. Biochim. Biophys. Acta 2013, 1829, 708-713. [CrossRef]

14. Fu, M.; Blackshear, P.J. RNA-binding proteins in immune regulation: A focus on CCCH zinc finger proteins. Nat. Rev. Immunol. 2017, 17, 130-143. [CrossRef]

15. Jura, J.; Skalniak, L.; Koj, A. Monocyte chemotactic protein-1-induced protein-1 (MCPIP1) is a novel multifunctional modulator of inflammatory reactions. Biochim. Biophys. Acta 2012, 1823, 1905-1913. [CrossRef]

16. Zhou, Z.; Miao, R.; Huang, S.; Elder, B.; Quinn, T.; Papasian, C.J.; Zhang, J.; Fan, D.; Chen, Y.E.; Fu, M. MCPIP1 deficiency in mice results in severe anemia related to autoimmune mechanisms. PLoS ONE 2013, 8, e82542. [CrossRef]

17. Liang, J.; Saad, Y.; Lei, T.; Wang, J.; Qi, D.; Yang, Q.; Kolattukudy, P.E.; Fu, M. MCP-induced protein 1 deubiquitinates TRAF proteins and negatively regulates JNK and NF-kappaB signaling. J. Exp. Med. 2010, 207, 2959-2973. [CrossRef]

18. Miao, R.; Huang, S.; Zhou, Z.; Quinn, T.; Van Treeck, B.; Nayyar, T. Targeted disruption of MCPIP1/Zc3h12a results in fatal inflammatory disease. Immunol. Cell Biol. 2013, 91, 368-376. [CrossRef] 
19. Garg, A.V.; Amatya, N.; Chen, K.; Cruz, J.A.; Grover, P.; Whibley, N. MCPIP1 Endoribonuclease Activity Negatively Regulates Interleukin-17-Mediated Signaling and Inflammation. Immunity 2015, 43, 475-487. [CrossRef]

20. Ruiz-Romeu, E.; Ferran, M.; Gimenez-Arnau, A.; Bugara, B.; Lipert, B.; Jura, J. MCPIP1 RNase Is Aberrantly Distributed in Psoriatic Epidermis and Rapidly Induced by IL-17A. J. Investig. Dermatol. 2016, 136, 1599-1607. [CrossRef]

21. Takaishi, M.; Satoh, T.; Akira, S.; Sano, S. Regnase-1, an Immunomodulator, Limits the IL-36/IL-36R Autostimulatory Loop in Keratinocytes to Suppress Skin Inflammation. J. Investig. Dermatol. 2018, 138, 1439-1442. [CrossRef]

22. Konieczny, P.; Lichawska-Cieslar, A.; Kwiecinska, P.; Cichy, J.; Pietrzycka, R.; Szukala, W. Keratinocyte-specific ablation of Mcpip1 impairs skin integrity and promotes local and systemic inflammation. J. Mol. Med. 2019, 97, 1669-1684. [CrossRef] [PubMed]

23. Monin, L.; Gudjonsson, J.E.; Childs, E.E.; Amatya, N.; Xing, X.; Verma, A.H. MCPIP1/Regnase-1 Restricts IL-17A- and IL-17CDependent Skin Inflammation. J. Immunol. 2017, 198, 767-775. [CrossRef]

24. Lichawska-Cieslar, A.; Konieczny, P.; Szukala, W.; Declercq, W.; Fu, M.; Jura, J. Loss of keratinocyte Mcpip1 abruptly activates the IL-23/Th17 and Stat3 pathways in skin inflammation. Biochim. Biophys. Acta Mol. Cell Res. 2021, 1868, 118866. [CrossRef]

25. Kridin, K.; Shani, M.; Schonmann, Y.; Fisher, S.; Shalom, G.; Comaneshter, D.; Batat, E.; Cohen, A.D. Psoriasis and Hidradenitis Suppurativa: A Large-scale Population-based Study. J. Am. Acad. Dermatol. 2018. [CrossRef]

26. Iwasaki, H.; Takeuchi, O.; Teraguchi, S.; Matsushita, K.; Uehata, T.; Kuniyoshi, K.; Satoh, T.; Saitoh, T.; Matsushita, M.; Standley, D.M.; et al. The IkappaB kinase complex regulates the stability of cytokine-encoding mRNA induced by TLR-IL-1R by controlling degradation of Regnase-1. Nat. Immunol. 2011, 12, 1167-1175. [CrossRef]

27. Deckers, I.E.; van der Zee, H.H.; Prens, E.P. Epidemiology of Hidradenitis Suppurativa: Prevalence, Pathogenesis, and Factors Associated with the Development of HS. Curr. Dermatol. Rep. 2013, 3, 54-60. [CrossRef]

28. Lima, A.L.; Karl, I.; Giner, T.; Poppe, H.; Schmidt, M.; Presser, D.; Goebeler, M.; Bauer, B. Keratinocytes and neutrophils are important sources of proinflammatory molecules in hidradenitis suppurativa. Br. J. Dermatol. 2016, 174, 514-521. [CrossRef]

29. van der Zee, H.H.; de Ruiter, L.; van den Broecke, D.G.; Dik, W.A.; Laman, J.D.; Prens, E.P. Elevated levels of tumour necrosis factor (TNF)-alpha, interleukin (IL)-1beta and IL-10 in hidradenitis suppurativa skin: A rationale for targeting TNF-alpha and IL-1beta. Br. J. Dermatol. 2011, 164, 1292-1298. [CrossRef]

30. Matusiak, L.; Bieniek, A.; Szepietowski, J.C. Increased serum tumour necrosis factor-alpha in hidradenitis suppurativa patients: Is there a basis for treatment with anti-tumour necrosis factor-alpha agents? Acta Derm. Venereol. 2009, 89, 601-603. [CrossRef]

31. Mozeika, E.; Pilmane, M.; Nurnberg, B.M.; Jemec, G.B. Tumour necrosis factor-alpha and matrix metalloproteinase-2 are expressed strongly in hidradenitis suppurativa. Acta Derm. Venereol. 2013, 93, 301-304. [CrossRef]

32. Emelianov, V.U.; Bechara, F.G.; Glaser, R.; Langan, E.A.; Taungjaruwinai, W.M.; Schroder, J.M.; Meyer, K.C.; Paus, R. Immunohistological pointers to a possible role for excessive cathelicidin (LL-37) expression by apocrine sweat glands in the pathogenesis of hidradenitis suppurativa/acne inversa. Br. J. Dermatol. 2012, 166, 1023-1034. [CrossRef] [PubMed]

33. Lister, M.F.; Sharkey, J.; Sawatzky, D.A.; Hodgkiss, J.P.; Davidson, D.J.; Rossi, A.G.; Finlayson, K. The role of the purinergic P2X7 receptor in inflammation. J. Inflamm. 2007, 4, 5. [CrossRef] [PubMed]

34. Salzer, S.; Kresse, S.; Hirai, Y.; Koglin, S.; Reinholz, M.; Ruzicka, T.; Schauber, J. Cathelicidin peptide LL-37 increases UVB-triggered inflammasome activation: Possible implications for rosacea. J. Dermatol. Sci. 2014, 76, 173-179. [CrossRef] [PubMed]

35. Manfredini, M.; Giuliani, A.L.; Ruina, G.; Gafa, R.; Bosi, C.; Zoppas, E.; Di Virgilio, F.; Bettoli, V. The P2X7 Receptor Is Overexpressed in the Lesional Skin of Subjects Affected by Hidradenitis Suppurativa: A Preliminary Study. Dermatology 2021, 237, 111-118. [CrossRef] [PubMed]

36. Killeen, M.E.; Ferris, L.; Kupetsky, E.A.; Falo, L., Jr.; Mathers, A.R. Signaling through purinergic receptors for ATP induces human cutaneous innate and adaptive Th17 responses: Implications in the pathogenesis of psoriasis. J. Immunol. 2013, 190, $4324-4336$. [CrossRef]

37. Zouboulis, C.C.; Del Marmol, V.; Mrowietz, U.; Prens, E.P.; Tzellos, T.; Jemec, G.B. Hidradenitis Suppurativa/Acne Inversa: Criteria for Diagnosis, Severity Assessment, Classification and Disease Evaluation. Dermatology 2015, 231, 184-190. [CrossRef]

38. Zouboulis, C.C.; Tzellos, T.; Kyrgidis, A.; Jemec, G.B.E.; Bechara, F.G.; Giamarellos-Bourboulis, E.J.; Ingram, J.R.; Kanni, T.; Karagiannidis, I.; Martorell, A.; et al. Development and validation of the International Hidradenitis Suppurativa Severity Score System (IHS4), a novel dynamic scoring system to assess HS severity. Br. J. Dermatol. 2017, 177, 1401-1409. [CrossRef] 